\title{
Enhancing flood resilience through improved risk communications
}

\author{
J. J. O'Sullivan ${ }^{1}$, R. A. Bradford ${ }^{1}$, M. Bonaiuto ${ }^{2}$, S. De Dominicis ${ }^{2}$, P. Rotko ${ }^{3}$, J. Aaltonen ${ }^{3}$, K. Waylen ${ }^{4}$, and \\ S. J. Langan ${ }^{4}$ \\ ${ }^{1}$ School of Civil, Structural and Environmental Engineering, University College Dublin, Ireland \\ ${ }^{2}$ Centro Interuniversitario di Ricerca in Psicologia Ambientale and Dipartimento di Psicologia dei Processi di Sviluppo e \\ Socializzazione, Sapienza Università di Roma, Rome, Italy \\ ${ }^{3}$ Suomen ympäristökeskus (Finnish Environment Institute), Helsinki, Finland \\ ${ }^{4}$ The James Hutton Institute, Aberdeen, Scotland
}

Correspondence to: R. A. Bradford (roisin.bradford@ucd.ie)

Received: 23 January 2012 - Revised: 14 June 2012 - Accepted: 15 June 2012 - Published: 20 July 2012

\begin{abstract}
A framework of guiding recommendations for effective pre-flood and flood warning communications derived from the URFlood project (2nd ERA-Net CRUE Research Funding Initiative) from extensive quantitative and qualitative research in Finland, Ireland, Italy and Scotland is presented. Eleven case studies in fluvial, pluvial, coastal, residual and "new" flood risk locations were undertaken. The recommendations were developed from questionnaire surveys by exploring statistical correlations of actions and understandings of individuals in flood risk situations to low, moderate and high resilience groupings. Groupings were based on a conceptual relationship of self-assessed levels of awareness, preparedness and worry. Focus groups and structured interviews were used to discuss barriers in flood communications, explore implementation of the recommendations and to rank the recommendations in order of perceived importance. Results indicate that the information deficit model for flood communications that relies on the provision of more and better information to mitigate risk in flood-prone areas is insufficient, and that the communications process is very much multi-dimensional. The recommendations are aimed at addressing this complexity and their careful implementation is likely to improve the penetration of flood communications. The recommendations are applicable to other risks and are transferrable to jurisdictions beyond the project countries.
\end{abstract}

\section{Introduction}

Focused flood risk communication serves to ensure that on receipt of some information, the public will behave in a way where appropriate and effective steps to reduce and mitigate the risk are taken (Yamada et al., 2011). Ineffectual communications or breakdowns in the channels along which information is conveyed have been cited as significant factors in the inadequate or failed response to previous natural disasters, including, for example, the Easter and summer floods of 1998 and 2007 in the UK (Horner and Walsh, 2000; Pitt, 2007) and the floods that resulted from Hurricane Katrina in 2005 (Gheytanchi et al., 2007). The reasons for failed communications are diverse. At one end of the spectrum, the complex social dynamic between government, responsible authorities and the public at large is at the forefront of the decision making process and in some instances, the political and social consequences of conveying the risk directs the communication process (Terpstra et al., 2009; Martens et al., 2009; United Nations, 2006). At the other, a failure by the public to simply comprehend received information is problematic (Twigger-Ross et al., 2009a; Du Plessis, 2002; Faulkner et al., 2007). Distrust and low confidence levels in the authorities that provide information (Basher, 2006; Renn and Levine, 1991), sometimes compounded by misleading or contradictory information reported in national and local media, can also serve to diminish the public response to flood risks (Martens et al., 2009; United Nations, 2006; Miles and Morse, 2007). Any or a combination of these factors may potentially contribute to the public being poorly informed of a flood risk with the consequence that the opportunity for 
maximising levels of resilience to this risk can be compromised. Effective communication between relevant stakeholders and the public at large is therefore a cornerstone of catchment flood risk management plans currently being prepared across Europe in compliance with the EU Floods Directive 2007/60/EC (EC, 2007).

Many communication strategies are based on an information deficit model (Irwin, 1995), which assumes that the public at risk are lacking in their knowledge of science and risk and that providing more or better information will produce more "rational" responses. Communities are not homogenous in how they understand and respond to information (Tapsell et al., 2005; Thrush et al., 2005) and such approaches are therefore unlikely to account for the large number of situational factors (physical characteristics, location) and social, cultural and psychological attributes (cognitive and affective) that influence flood warning response by inhibiting or enabling action by individuals in flood prone locations (Tobin and Montz, 1997; Parker et al., 2007). How risk information is assessed is dependent on an individual's judgement and perception of the risk. This is in turn influenced by the socio-cultural context of the risk, how this is subjectively viewed (Slovic, 2000; Vahabi, 2007) and how it fits in with an individual's everyday experience of the risk and the associated risk information (Pidgeon et al., 2003; Horlick-Jones, 2007). Furthermore, communication about risk is interpreted in light of wider changes in demographic patterns, communication practices and norms together with awareness of and expectations about risks (Beck, 1992). The ambiguity created by the differences in how people process information, referred to as interpretive (Brugnach et al., 2008) or decision uncertainty (as different to probabilistic or non-probabilistic uncertainty), represents a weakness in information deficit models for flood risk communications. It is unsurprising therefore that, as reported by Twigger-Ross et al. (2009b) and Miceli et al. (2008), changes or improvements to any single factor of risk communication strategies based on the information deficit model are unlikely to achieve significant changes in response.

This paper presents the findings of the URFlood project (September 2009 to August 2011) funded under the 2nd ERA-Net CRUE research call. The project utilised extensive quantitative (survey questionnaires) and qualitative research (focus groups and structured interviews) to identify obstacles and barriers in flood communication strategies in the partner countries of Finland, Ireland, Italy and Scotland. While Tinker and Galloway (2009) identified the requirement for good communications in the pre-flood (risk awareness and flood preparedness promotion), flood (encompassing flood warnings) and post-flood (recovery) phases, this research focused on communications prior to and during flood events. Furthermore, while resilience is multi-faceted, the social (rather than the physical, economic, institutional and ecological) dimension is of particular importance in the context of flood risk communications and is dealt with in this paper. Although resilience in this regard is defined as the capacity of an individual (or community) to adapt (by resisting or changing) in order to reach and maintain its survival and functioning, the social aspect less formally relates to the capacity of individuals to recover with minimal disruptions (Samuels et al., 2005; UNISDR, 2005; Manyena, 2006).

The paper assumes that those who engage with (and respond to) flood communications will have higher resilience levels. Flood information and warnings in this regard are considered a resource that flows through a network of different actors and is converted to knowledge in a way that has a positive influence on practices. By identifying differences in how individuals in high and low resilience groupings acquire, interpret and respond to flood awareness and preparedness information and flood warnings, practical and easily implementable recommendations for improving the penetration of flood risk communications between key stakeholders (the at-risk public, national and local authorities and emergency services) are presented. Viewing the communications process in this way is consistent with a knowledge systems approach of the type advocated by Roling and Engel (1990). Such approaches inherently include a more holistic interpretation of risk communication processes and results suggest they may offer improvements over the information deficit model through better accounting of how knowledge is used in decision making to achieve an effective behavioural response, rather than focussing solely on the content of the communication itself.

Furthermore, information deficit communication models tend to follow a hierarchical top-down approach with little engagement of end-users and limited bottom-up information transfer. While this is recognised as a drawback, an entirely bottom-up approach, where the public control all decisions is also likely to be ineffective (Roling and Engel, 1990). Given that the proposed recommendations are derived from at-risk individuals and include provisions designed to facilitate continued engagement between the public and responsible authorities, the findings support two-way communications models that are neither fully top-down nor bottom-up but still have the at-risk communities at their centre, as is now preferable (Sene, 2008; Basher, 2006; United Nations, 2006).

This paper describes an extensive survey of in excess of 1100 participants across four European countries. Results therefore facilitate comparisons amongst sub-groups divided in terms of demographic factors (including gender, age, education level, employment status, nationality, dwelling type), risk types and flood histories. Where differences in responses are clearly attributable to these factors, these are reported. 


\section{Methodology}

\subsection{Questionnaire survey}

The quantitative research involved self-completion questionnaire surveys in eleven "at-risk" case studies in Finland, Ireland, Italy and Scotland (Fig. 1). Case study locations were selected in consultation with technical steering committees in the partner countries and included areas exposed to fluvial (river flooding), pluvial (rainfall generated flooding), coastal (inundation of land by sea water), "new" (areas recently flooded with no significant flood history) and residual (areas in the vicinity of structural flood defences) flood risks (Table 1). A total of 4546 questionnaires were circulated using a mixed mode methodology to households and small businesses. Postal dissemination facilitated surveys of larger geographical areas but for more compact case study locations, questionnaires were delivered in person. Targeted properties were those vulnerable to existing flood risks but which may not necessarily have been flooded previously. Properties within the theoretical 100-yr flood contour for fluvial floods and the 200-yr contour for coastal floods, determined using GIS analyses, comprised the Irish case study sample. In other countries, respondents were targeted from within the largest historical flood contour, while also including at-risk areas straddling the outer limit of these contours. Press releases in local media prior to circulating the questionnaires together with letters of reminder in the week when returns were due were issued to encourage responses. A total of 1142 completed questionnaires were returned, equating to an overall response rate of approximately $25 \%$. Response rates however, varied across the case studies depending on the sampling method. Returns of between $15 \%$ and $37 \%$, consistent with typical values of approximately $20 \%$ reported by Kelley et al. (2003), were obtained from postal surveys, but considerably higher response rates of between $58 \%$ and $88 \%$ were achieved in case studies where surveys were delivered and collected in person (Rome, Vibo Valentia and Huntly). Questionnaires (available at http://www.macaulay. ac.uk/urflood/case_studies.php) focussed on key themes that identified levels of (i) risk awareness, (ii) preparedness and (iii) worry, but also ascertained (iv) flood communications and warnings that were previously received, (v) the manner in which these were disseminated and (vi) how best this could be improved in the future. The structure of the questionnaires adhered to the key principles of questionnaire design. In this regard the majority of questions were short and simple and of a pre-coded and prompted nature with a meaningful Likert scale to provide a good spread of answers. Preliminary piloting of the questionnaires ensured that the potential for misunderstanding was minimised and that questions were precise and unambiguous in their nature. While questionnaires across the partner countries were designed to be consistent and contained common questions to address the

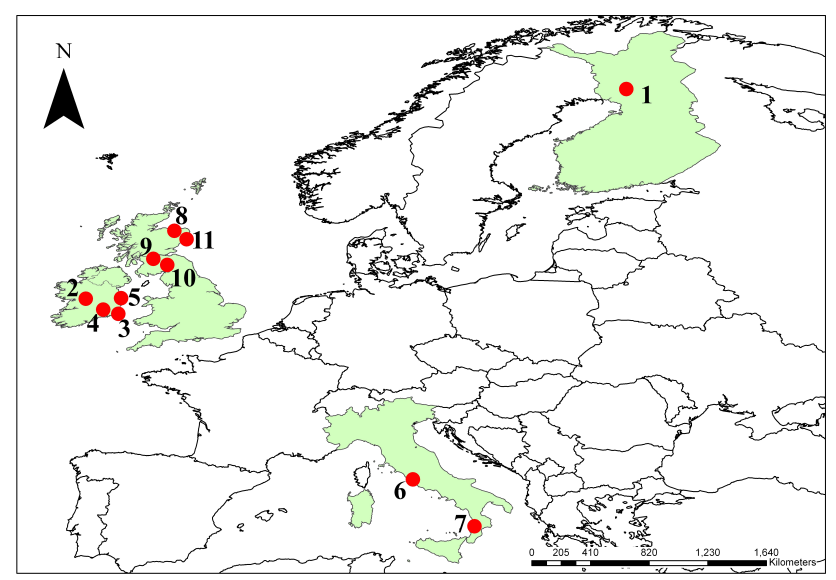

Fig. 1. URFlood project case study locations (numbers relate to Table 1).
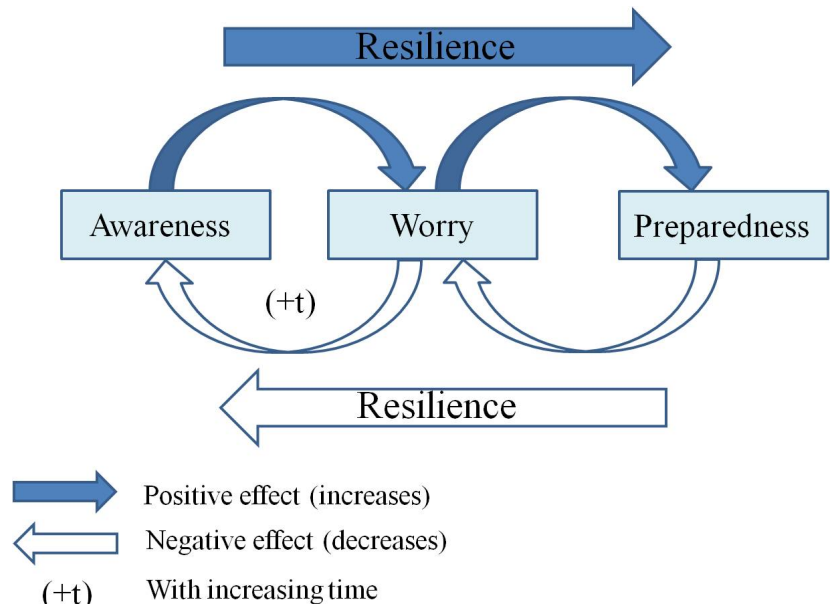

Fig. 2. Relationship between elements of risk perception (adapted from Raaijmakers et al., 2008).

key issues, other questions to address flood risk issues that were specific to particular countries or regions were also included.

Data were analysed separately for each partner country and collectively across countries using the SPSS (originally Statistical Package for the Social Sciences) predictive analytics software package (SPSS, 2009). Chi-square tests, independent samples t-tests and one-way analysis of variance (Anova) were used, with the critical significance value (p-value) set at 0.05 .

\subsection{Development of recommendations}

Developing recommendations for flood communications based on behavioural differences along a gradient of social resilience necessitated a division of the survey sample into groups of low, moderate and high resilience. This in turn required a conceptual model that discriminated in 
Table 1. Case study sites, risk types ( $\mathrm{f}=$ fluvial, $\mathrm{p}=$ pluvial, $\mathrm{c}=$ coastal, $\mathrm{r}=$ residual and $\mathrm{n}=\mathrm{new}$ ), flood history and questionnaire dissemination details.

\begin{tabular}{|c|c|c|c|c|c|c|c|c|c|c|c|}
\hline \multirow[t]{2}{*}{ Country } & \multirow[t]{2}{*}{ Case study site } & \multirow[t]{2}{*}{ Catchment size } & \multicolumn{5}{|c|}{ Risk type } & \multirow[t]{2}{*}{ Past flood events } & \multirow[t]{2}{*}{ No. issued } & \multirow[t]{2}{*}{ No. returns } & \multirow[t]{2}{*}{$\%$ returns } \\
\hline & & & $\mathrm{f}$ & $\mathrm{p}$ & $\mathrm{c}$ & $\mathrm{r}$ & $\mathrm{n}$ & & & & \\
\hline Finland & 1. Rovaniemi & $51127 \mathrm{~km}^{2}$ & $\checkmark$ & & & & & Major: 1993 Minor: damage yearly & 1678 & 325 & $19.4 \%$ \\
\hline \multirow[t]{5}{*}{ Ireland } & 2. Ballinasloe & $1590 \mathrm{~km}^{2}$ & $\checkmark$ & & & & $\checkmark$ & Little until November 2009 & 353 & 84 & $23.8 \%$ \\
\hline & 3. Wexford Town & $6.39 \mathrm{~km}^{2}$ & & & $\checkmark$ & & & Oct 2004 & 494 & 78 & $15.8 \%$ \\
\hline & 4. Clonmel & $2173 \mathrm{~km}^{2}$ & $\checkmark$ & & & $\checkmark$ & & Six severe floods since 1995 , plus minor floods & 649 & 126 & $19.4 \%$ \\
\hline & 5. Dublin & $125 \mathrm{~km}^{2}$ & $\checkmark$ & $\checkmark$ & $\checkmark$ & $\checkmark$ & & Severe tidal floods in Feb 2002. Many other events & 676 & 148 & $21.9 \%$ \\
\hline & & & & & & & & Total Ireland: & 2172 & 436 & $20.1 \%$ \\
\hline \multirow[t]{3}{*}{ Italy } & 6. Rome & $445 \mathrm{~km}^{2}$ & $\checkmark$ & $\checkmark$ & & & & Multiple floods from the Tiber (last 2008) & 150 & 132 & $88.0 \%$ \\
\hline & 7. Vibo Valentia/Bivona & $46 \mathrm{~km}^{2}$ & & $\checkmark$ & $\checkmark$ & & & July 2006 pluvial flood. Other floods nearby & 120 & 104 & $86.7 \%$ \\
\hline & & & & & & & & Total Italy: & 270 & 236 & $87.4 \%$ \\
\hline \multirow[t]{6}{*}{ Scotland } & 8. Huntly & $1266 \mathrm{~km}^{2}$ & $\checkmark$ & & & & & Nov 2009 "worst in living memory" & 86 & 50 & $58.1 \%$ \\
\hline & 9. Glasgow/Whitecart & $250 \mathrm{~km}^{2}$ & $\checkmark$ & & & $\checkmark$ & & More than 20 significant floods in $80 \mathrm{yr}$ & 180 & 37 & $20.6 \%$ \\
\hline & 10. Moffat & $960 \mathrm{~km}^{2}$ & $\checkmark$ & & & & & July 2011 plus many others & 60 & 21 & $35.0 \%$ \\
\hline & 11. Newburgh & $550 \mathrm{~km}^{2}$ & & & $\checkmark$ & & & None but classified as vulnerable by SEPA & 100 & 37 & $37.0 \%$ \\
\hline & & & & & & & & Total Scotland: & 426 & 145 & $34.0 \%$ \\
\hline & & & & & & & & Total sample: & 4546 & 1142 & $25.1 \%$ \\
\hline
\end{tabular}

a reasonably simple way between factors that enhance or reduce resilience. The recognition that risk perception is a major pillar of social resilience (Marshall and Marshall, 2007) that shapes the way individuals react, behave and cope with risks (Schumm, 1994) facilitated the use of the Raaijmakers et al. (2008) concept of risk perception (Fig. 2) for this purpose. Figure 2 defines risk perception through a relationship between flood risk awareness, worry and preparedness. Increasing any or a combination of these increases the perception of risk and, in so doing, contributes to enhanced social resilience. Over time, worry and hence awareness will decrease.

Differences in the questionnaires used in the partner countries necessitated a two-stage approach for developing the proposed recommendations for flood risk communications. Implementation of Fig. 2 requires that levels of risk awareness, worry and preparedness of respondents be assessed. While supported in results from Irish and Scottish case studies, these three elements were explicitly assessed in Finnish and Italian case studies (Table 2) and the results of these were used in the first stage of the analyses in which "core" recommendations were derived. This involved dividing participants in the Finnish and Italian case studies into low, moderate and high resilience groupings based on their perception of risk as contextualised in Fig. 2.

Resilience groupings were based on the indicators and scoring system in Table 2 and respondents with scores of 0 $1,2-3$ and 4-6 were classified as being of low, moderate and high resilience, respectively. Features of how individuals obtain, interpret and respond to flood related information and flood warnings were statistically correlated to the different resilience groupings to develop recommendations for effective flood communications.
In addition to the development of core recommendations, other characteristics were identified from questionnaire returns of the full sample $(n=1142)$ that although not statistically correlated to elevated levels of awareness, preparedness and worry were considered by respondents to be important aspects of flood communications. These were included as "supplementary" recommendations in the proposed communications framework.

\subsection{Testing recommendations}

In addition to questionnaire surveys, qualitative research was undertaken to test the resonance of the recommendations with members of the public, responsible authorities and emergency services involved in flood risk management. This involved a combination of focus groups and in-depth structured interviews across the partner countries (Table 3) that adhered to a common topic guide. This element of the project was designed to discuss the perceived obstacles and barriers in existing communications strategies identified in the questionnaire surveys and explore ways in which the recommendations could best be implemented. Participants in the qualitative research were also required to rank the core and supplementary recommendations in terms of their perceived importance.

\section{Results and discussion}

\subsection{Description of sample}

Good practice for studies of this type dictates that the representativeness of the sample be ascertained. Data collected from the four partner countries were combined into a single transnational sample and compared with European census data (European Commission, 2011). Results indicate that the 
Table 2. Key variables investigated in questionnaires in Finland (F), Ireland (IR), Italy (IT) and Scotland (S) as well as scoring system for resilience profiling (Score of 0-2).

\begin{tabular}{|c|c|c|c|c|c|c|c|c|}
\hline Key topic & Key variable & Score of 0 & Score of 1 & Score of 2 & $\mathrm{~F}$ & IR & IT & $\mathrm{S}$ \\
\hline Awareness & $\begin{array}{l}\text { Perception of living } \\
\text { in a flood risk area } \\
\text { (Yes/Probably/No) }\end{array}$ & Not aware & $\begin{array}{l}\text { Some } \\
\text { awareness }\end{array}$ & Fully aware & $\checkmark$ & $\checkmark$ & $\checkmark$ & $\checkmark$ \\
\hline Worry & $\begin{array}{l}\text { Degree of worry } \\
\text { regarding floods (Likert } \\
\text { scale: Not worried at all } \\
\text { - greatly worried) }\end{array}$ & Not worried & $\begin{array}{l}\text { Moderately } \\
\text { worried }\end{array}$ & Greatly worried & $\checkmark$ & & $\checkmark$ & \\
\hline Preparedness & $\begin{array}{l}\text { Self-assessed levels of } \\
\text { personal preparedness } \\
\text { (Likert scale: Not } \\
\text { prepared at all - very } \\
\text { well prepared) }\end{array}$ & Not prepared & $\begin{array}{l}\text { Moderately } \\
\text { prepared }\end{array}$ & Well prepared & $\checkmark$ & $\checkmark$ & $\checkmark$ & \\
\hline
\end{tabular}

Table 3. Qualitative data collection in the partner countries.

\begin{tabular}{|c|c|c|c|}
\hline Partner Country & Method used & $\begin{array}{l}\text { Number of } \\
\text { participants }\end{array}$ & Participants targeted \\
\hline Finland & Focus group & $\begin{array}{l}2 \text { focus groups, } \\
10 \text { and } 15 \\
\text { participants } \\
\text { respectively }\end{array}$ & $\begin{array}{l}\text { 1. Regional environment authorities working with floods } \\
\text { 2. Experts from Ministry of Agriculture and Forestry, Ministry } \\
\text { of Transport and Communications, Ministry of Social Affairs } \\
\text { and Health, Finnish Regional Councils, Finnish Meteorologi- } \\
\text { cal Institute, Association of Towns and Municipalities, Finnish } \\
\text { Environment Institute, and Centre for Economic Development, } \\
\text { Transport and the Environment }\end{array}$ \\
\hline Ireland & Interview & 13 & 1. Public at risk in Dublin case study area \\
\hline Italy & Interview & 74 & $\begin{array}{l}\text { 1. Public at risk in Rome and Vibo Valentia }(n=50) \\
\text { 2. "Experts" chosen from authorities involved in flood risk } \\
\text { management (Civil Protection, Fire-Fighters, Municipality of } \\
\text { Rome, Municipality of Vibo Valentia and the Department of } \\
\text { Geological Services) }(n=24)\end{array}$ \\
\hline Scotland & Focus group & $\begin{array}{l}2 \text { focus groups, } \\
10 \text { and } 12 \\
\text { participants } \\
\text { respectively }\end{array}$ & $\begin{array}{l}\text { 1. Scottish Flood Forum-representatives include local } \\
\text { authorities, national agencies, emergency services, government, } \\
\text { researchers and public at risk } \\
\text { 2. Moffat flood action group- public at risk }\end{array}$ \\
\hline Total number participants: & 134 & & \\
\hline
\end{tabular}

sample is even in terms of gender, comprising $51 \%$ and $49 \%$ male and female respondents, respectively. On average, $42 \%$ of the sample reached a tertiary level of education, varying from $20 \%$ in Italy to $59 \%$ in Scotland. European statistics indicate that on average, $25 \%$ of the population in Ireland, Italy and the UK achieve tertiary levels of education, ranging from $13 \%$ in Italy to approximately $30 \%$ in Ireland and the UK. The above average values within the sample perhaps reflect the lower unemployment levels that were $5 \%$ compared to the European average of $8.5 \%$. The majority of the sample was aged between 35 and $64 \mathrm{yr}$, with those under 35 be- ing slightly underrepresented. $23 \%$ were over the age of 65 , comparing well with the partner country average, determined from census data to be $21 \%$. The underrepresentation of younger respondents is not thought to be due to survey conditions as a mixed dissemination approach was used. Data confirms that the sample is reasonably representative of the overall European population and is socio-demographically diverse. The large sample size and sampling methods used help ensure that the sample is statistically robust (Kelley et al., 2003) and that the findings can be generalised to increase the transnational importance of the study. 


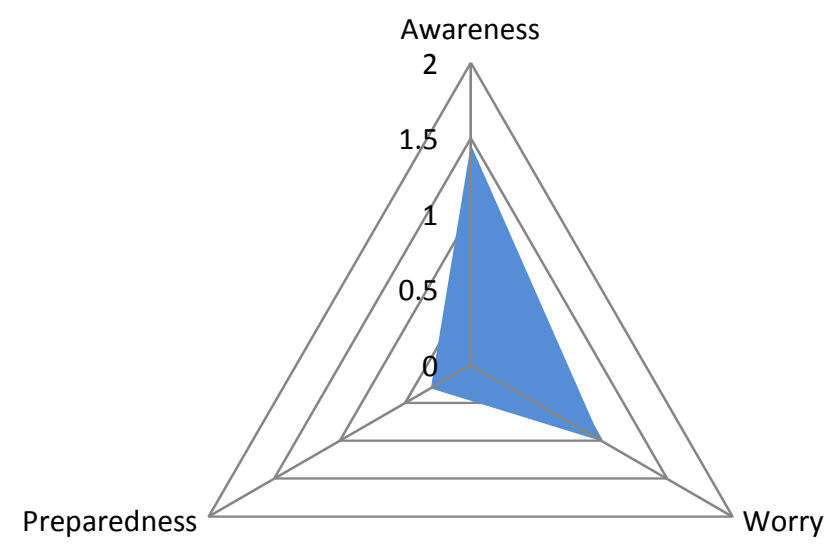

Fig. 3. Average scores for risk perception characteristics in Finland and Italy $(n=529$; non response $=32)$.

\subsection{Core recommendations}

Applying the conceptual framework of perception and resilience in Fig. 2 to Finnish and Italian participants $(n=$ 529 , non-response $=32$ ) produced low, moderate and high resilience groupings comprising $85(16 \%), 259(49 \%)$ and $185(35 \%)$ respondents, respectively. Figure 3 indicates that the three components of social resilience in Fig. 2 are not equally represented in the sample and that levels of resilience are derived from high levels of awareness and worry rather than preparedness. Results, therefore, identify an inclination amongst participants to leave responsibility for flood mitigation in the hands of responsible authorities, rather than taking ownership of their own risk, with the likely consequence of diminishing both individual and community capacity to deal effectively with flood events. Such thinking represents a barrier to effective flood communication that can be addressed by ensuring that flood communications strategies clearly define the remit and responsibilities of the various agencies involved in all phases (pre, during and post-flood) of flood risk management. The lack of clarity amongst respondents regarding the roles and responsibilities of agencies engaged in flood risk management was reflected in interviews in Irish case studies where it was noted that "there seemed to be a 'passing of the book' approach adopted" and "no group was willing to accept any form of authority or responsibility". Publicising clearly defined roles of all stakeholders in the flood risk management chain will enable the public to differentiate between their own responsibility to protect themselves and that of the relevant authorities. An indirect benefit of this recommendation is that individual preparedness levels will be increased, thereby increasing capacity to reduce the adverse consequences of floods.

Given that resilience to floods may be enhanced by an acceptance amongst the public to take a proactive role in flood risk management, the provision of information that promotes risk awareness and good practice preparedness measures is essential. Respondents were asked how they perceived the importance of flood preparatory information provided in advance of an event (on a scale of 1-5 with 1 being "very important" and 5 being "not at all important"). Two sample ttests showed females $(n=283)$ within the sample and those living in single story dwellings $(n=176)$ to place greater importance on the provision of this information $(t=3.1$, $d f=458, p=0.002$ and $t=-3.3, d f=361, p=0.001$, respectively).

Results of a one-way analysis of variance (Finnish and Italian respondents; $n=529$ ) also showed that those who considered these pre-flood communications to be important were more likely to be in the high resilience group (1-way Anova, $F=4.7, p=0.009$ ). The provision of information and advice, therefore, that raises awareness of risk and identifies and outlines specific ways of reducing the risk of damage to properties and their contents can promote higher preparedness levels. Furthermore, the Irish case studies indicated that the penetration of a once-off national flood preparedness campaign (termed Plan, Prepare and Protect) launched in 2005 was almost negligible five years later. For maximum benefit, pre-flood communications are therefore required on an ongoing and regular basis rather than in one-off information campaigns that are sometimes part of a response to extreme events.

In this context, suggestions for ways of providing preflood preparedness information were discussed in the qualitative research of the project. Methods that were mentioned as being useful included mass media sources (newspapers, radio, television); and printed pamphlets circulated by post or made available at recognised access points, such as police stations, council offices and libraries. Disseminating flood awareness and preparedness information through "lo-call" flood-help telephone lines, local flood groups and residents associations was also cited in responses. Discussions in focus groups and structured interviews also indicated that higher preparedness levels could be obtained through communications that not only explain how best to prepare but also highlight the benefits of being prepared. Participants expanded on this issue by noting that while the main benefits are likely to be financial (reduced recovery and insurance costs together with increased property prices), simple preparedness could help ensure that sentimentally important items remain safe. It was also noted that the provision of preparedness advice from household insurers has added weight and reinforces the economic savings that are possible through the implementation of low-cost, reasonably simple measures. Being cognisant of the specific needs of vulnerable groups within the community (the elderly, families with young children, residents of single storey dwellings for example) and reaching these groups through targeted approaches in communications strategies was also considered to be important by study participants.

Although the direct provision of flood related information is recommended, background research in the partner 


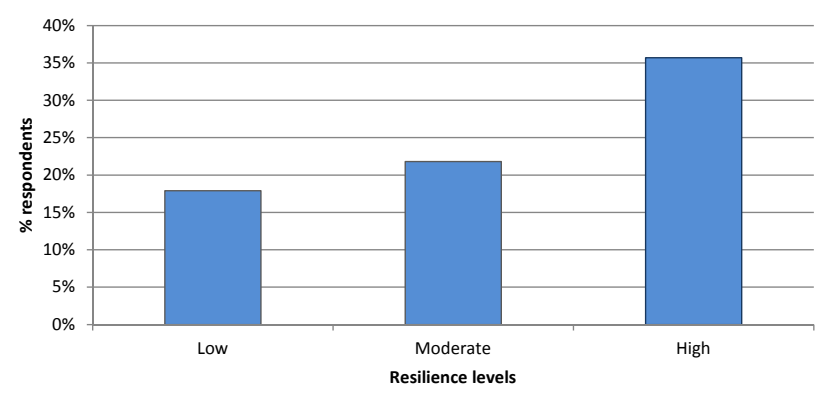

Fig. 4. Influence of visiting information websites on resilience levels in Finland and Italy $(n=529$; non-response $=32)$.

countries indicated that websites of the national, regional and local agencies responsible for flood risk management contained significant material pertaining to all aspects of floods (including warnings, preparedness information and maps). Awareness of these web resources across the project case studies, however, was shown to be low. This was epitomised by one Scottish focus group attendee proclaiming to be "unaware that this website existed as there was no communication or information posts or otherwise" highlighting its existence. In Finland and Italy, only $25 \%$ of respondents were aware of their national, regional or local flood websites. A similar level of awareness was reported in Scotland but this reduced to $9 \%$ in Irish case studies. Across the full project sample $(n=1142)$, both the elderly (over $65 \mathrm{yr}$ ) and those with lower achieved education levels were shown to be less likely to access websites for flood related information $(t=2.7, d f=777, p=0.008$ and chi-square $=16.8$, $d f=1, p<0.001$, respectively). However, $74 \%$ of those that had accessed the websites were shown to have found the information to be of use. A chi-square test showed that a greater percentage of high resilience respondents than those in the moderate and low resilience groups had previously accessed flood information websites (Fig. 4) (chi-square $=14.3$, $d f=2, p=0.001)$. Scope clearly exists for improving the awareness and usage of currently available web resources and a recommendation from this study is that initiatives for this should ideally be included in all flood risk communication strategies. Making this information available through the use of simple URLs would facilitate easier access and it was suggested by representatives of various authorities in the Scottish focus group as well as members of the public in Irish interviews that an increased awareness of these information sources could be achieved by additional promotional activities at times that coincide with extreme periods of prolonged rainfall, large scale floods occurring elsewhere or on anniversaries of previous floods.

The provision of information alone is not sufficient to generate a response. Actions will only occur if the recipients of the information understand the message. If this is not the case, inaction or inappropriate action from a misinterpretation of the message is likely. All case studies of the project identified low levels of understanding of the probabilistic terminologies that describe flood magnitudes and found that a disconnect often exists between the language used by the engineering community and that understood by the public at large. The $1 \%$ annual exceedance probability (AEP) is commonly used across Europe to describe a flood that has a $1 \%$ chance of being equalled or exceeded in a single year. Participants in the Italian and Irish case studies were asked whether they understood this term and in Finland this understanding was tested by requesting that respondents identify from a given list the statement that describes most appropriately the meaning of the $1 \%$ AEP. Figure 5 shows that understanding of this term is positively related to resilience levels (chi-square $=7.2, d f=2, p=0.028$ ) and provides support for the assertion that improving the understanding of the complex concepts of risk is related to greater awareness and enhanced levels of social resilience. Within the sample of Finnish, Irish and Italian respondents $(n=997)$, females (chi-square $=12.7, d f=1, p<0.001$ ) and those over $65 \mathrm{yr}$ (chi-square $=5.2, d f=1, p=0.022$ ) were less likely to understand the $1 \%$ AEP. Respondents in case studies where residual flood risk remained (Irish participants in the Clonmel and Dublin case studies and Scottish participants in the Glasgow/ Whitecart case study; $n=311$ ) were also shown to be less likely to understand the $1 \%$ AEP term (chisquare $=8.3, d f=1, p=0.004$ ), perhaps supporting the assertion that structural flood defences promote a detachment from a sense of risk in individuals residing in these areas.

The terminology through which risk may be most effectively conveyed to the public was further explored in the four Irish case studies $(n=436)$ in which respondents were asked to identify their preferred notation from a list of commonly used terms. Highest preferences $(46 \%)$ were recorded for risk definition in terms of the 100 -yr flood. Describing exceedance levels in terms of 1 in 100 chance events and 1 in 100 floods were preferred by $27 \%$ and $21 \%$ of the sample respectively, with the $1 \%$ AEP representing the least popular terminology being chosen by only $6 \%$ of respondents. However, no clear correlation between preferred terminology and actual understanding of that term was observed (Fig. 6). A balance is required in communications between using sufficiently simple language that is understandable to all and using over-simplified terms that may reduce topic salience. For this reason, it is important that flood risk communications are presented in terms that can be easily comprehended by a non-technical audience and are direct, brief and focussed. Qualitative research identified that expressing risk in terms of previous flood events is preferable by the public in this sample.

\subsection{Supplementary recommendations}

In addition to the four core recommendations, two further recommendations for effective flood communications are proposed. While not explicitly derived through correlation 


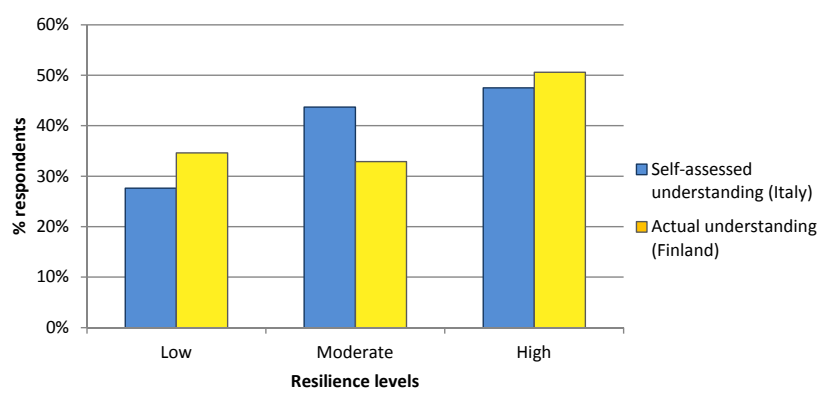

Fig. 5. Influence of understanding $1 \%$ AEP term on resilience levels in Finland $(n=295$; non response $=30)$ and Italy $(n=234$; nonresponse $=2$ ).

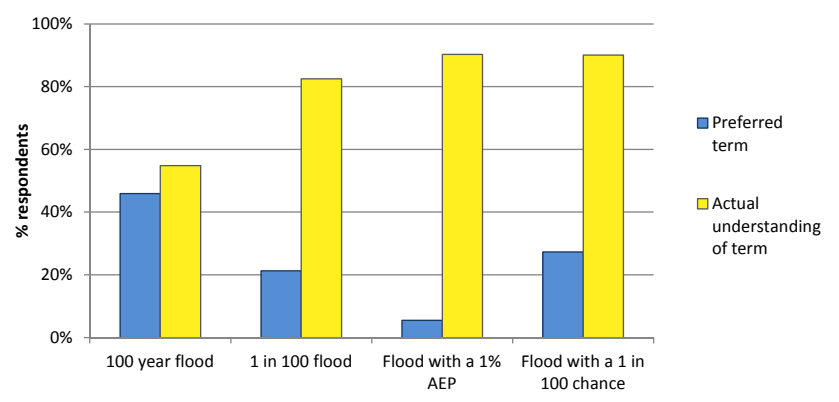

Fig. 6. Difference between preferred terminology and actual understanding of that term in Ireland $(n=366$; non-response $=70)$.

to the social resilience model (Fig. 2), the recommendations are nonetheless noteworthy.

The first of these is that for a flood message to reach all intended recipients, multiple channels of communication are required. Communications about floods are not always given through methods that the public at risk prefer. Respondents in the Finnish, Irish and Scottish samples $(n=906)$ were asked to identify sources through which they would like to receive general flood information and flood warnings. Multiple citations were permitted. Figure 7 shows that respondents opted for more options for flood warnings than for general flood information showing that a greater number of sources are preferred for flood warning. However, in-person visits, radio and television announcements as well as text messages to mobile phones were popular for both types of communication. While SMS messaging may be more efficient for disseminating warnings in a crisis, they may also be suitable for general flood information. Such information could include links to websites and flood information lines where advice on preparation can be obtained (for example Floodline in the UK), creating awareness of current information sources as well as details of who to contact during an emergency situation. Such information can be stored on a mobile phone and easily accessed during times of crisis. Similarly, while phone calls are useful for issuing warnings, the use of this method for disseminating general flood information

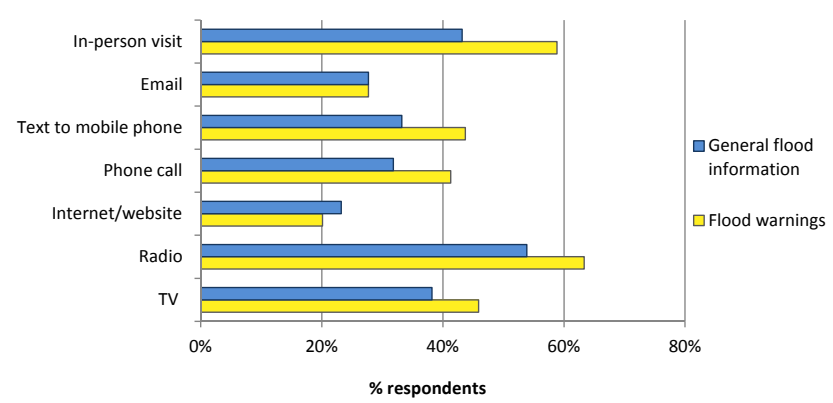

Fig. 7. Preferred communication methods for receiving flood information and warnings in Finland, Ireland and Scotland $(n=906$; non-response $=0$ ).

represents a proactive approach in providing the opportunity for at-risk residents to discuss preparation options and develop understanding of the warning system and the terminology that may be used. It is recognised however, that this will be resource intensive. Correlations between these preferred methods and demographic factors of the sample were explored. Although disseminating information and warning information through websites was the least preferred method for the full sample, independent sample t-testing showed that the use of web resources together with SMS messaging was more popular with respondents of a younger age $(t=-4.6, d f=762, p<0.001)$. Female respondents together with those with reduced proficiency in the native language of a given country (fluency levels were requested in surveys) expressed a preference for receiving information through television (chi-square $=9.6, d f=1, p=0.002$ and chi-square $=18.3, d f=1, p<0.001$, respectively). While some correlations might be expected, reasons for others are less clear. However, the variations in preferred communications media indicate that single mode messaging or warnings will not account for the demographic diversity within a typical community and no single communication mode will reach "all of the people all of the time". Therefore, multiple methods will be required to help ensure that information is received by as broad a target audience as possible and provision for this needs to be included in any communication strategy for it to be effective.

Communication without trust and credibility is likely to have very little impact. The level of trust that the public had for authorities (national bodies, local authorities and emergency services) with a role in flood risk management was explored in the Irish and Scottish case studies $(n=580$; nonresponse $=1$ ) and is shown in Fig. 8. Levels of trust in the emergency services were shown to be significantly higher than for both national (government) bodies and local authorities and were also higher for female $(n=258)$ respondents $(t=-2.1, d f=5150, p=0.035)$. In addition, highest levels of trust in the emergency services were recorded amongst Irish $(n=436)$ respondents (1-way Anova, $F=27$, 


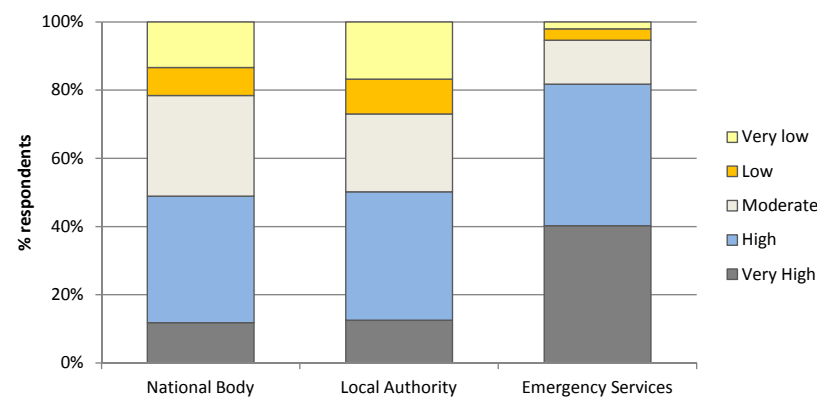

Fig. 8. Trust in public agencies in Ireland and Scotland $(n=580$; non-response $=1$ ).

$p<0.001)$. These higher trust levels may be attributed to the ease of accessibility in contacting emergency services as contact numbers are known and can be used at any time of day. Emergency services also have a clear remit in terms of emergency response with which members of the public are familiar - roles and responsibilities of national and local authorities have been shown in this research to be less well understood. Lower levels of trust in national and local bodies is a concern given that all flood related communication and flood warnings in Ireland and Scotland (as with many countries in Europe) originate from these authorities (with the role of the emergency services being more focussed on flood incident management). Existing research indicates that trust can be developed by constructive interactions and dialogue between the relevant parties (Frewer, 2004; Hoppner et al., 2010). Evidence from this study however, indicates that low trust levels can result in a reluctance to engage with national and local authorities on flood related matters; as one interviewed respondent in Ireland stated "I would tell nobody (of an impending flood) as no heed would be taken and my telling would get lost in some system somewhere". A significant number of respondents in the Irish and Scottish case studies $(n=410)$ had in the past contacted national and local authorities and emergency services on flood matters. Respondents reported significantly more positive exchanges with the emergency services than with flood management agencies, with approximately one third of all approaches made to national bodies and local authorities being ignored (Fig. 9). The perceived inertia within the organisational structures of flood agencies is reflected in the observation of a previously flooded member of the public in Ireland that there is "no point contacting (the flood risk authorities), they never respond and flooding always happens when phones are not answered". In addition, the perception of being listened to was found to directly influence trust in authorities (1-way Anova, $F=20.3, p<0.001$ ).

Results suggest that flood information in the project countries is disseminated within a hierarchical framework from national bodies, through local authorities and emergency services to the public at risk. The linear nature of such top-down

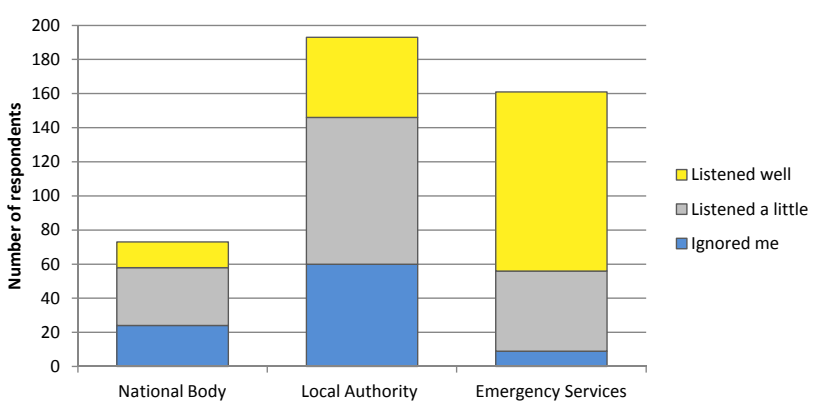

Fig. 9. Assessment of how public queries to national bodies $(n=$ $73)$, local authorities $(n=193)$ and emergency services $(n=161)$ were received in Ireland and Scotland.

structures offers little opportunity for engagement of endusers and is not conducive to developing constructive feedback channels. This drawback is important in that feedback processes are essential in ensuring the system continuously evolves and improves based on learning from previous experiences. The issue was raised on a number of occasions in the qualitative research and the comment by one participant in an Italian interview expressing the wish that "all authorities associated with the flooding conditions would communicate with the public more" reflects the problem. For this reason, the establishment of two-way communication channels between authorities and the public also forms a supplementary recommendation in this study.

The core and supplementary recommendations from the study were combined to form a "picture" of good practice in flood communications to enhance social resilience (Fig. 10). The perceived importance of the six recommendations was investigated in the qualitative case study research and the rank of each (from 1 to 6 with 1 being the most important) is also included in Fig. 10. All six recommendations are applicable to pre-flood communications while recommendations C.1 to C.3 together with S.1 can also apply to flood warnings.

\section{Conclusions}

The URFlood project, funded under the 2nd ERA-Net CRUE research call and focussed on developing improved communications between the various stakeholders involved in flood risk management is presented. By analysing the views and perspectives of individuals in at-risk communities with more minor inputs from flood risk managers in local and national authorities and emergency service personnel, a "picture" for guiding good practice flood communications has been developed. While agencies in the four countries studied provide information (albeit through different means and to varying degrees) on flood risk, results indicate that current dissemination could be significantly improved. It appears that the information deficit model of flood risk communications in which 


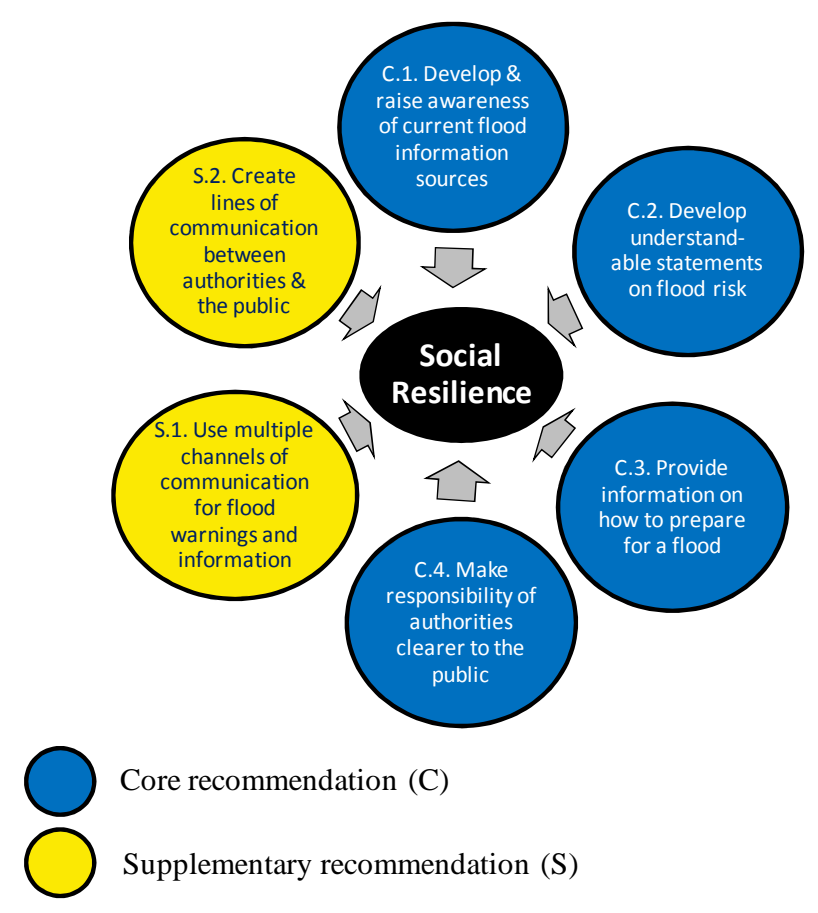

Fig. 10. Social resilience framework for improving flood risk communications, with rank order as defined by respondents and with core and supplementary status according to their relationship with resiliency.

the provision of more and perhaps better information to mitigate risk in flood-prone areas is insufficient and that the communications process is very much multi-dimensional. Participants of this study in many cases had knowledge of potential risks but displayed an alarming reluctance to prepare or respond appropriately to this risk. Considerable scope therefore exists for improving flood risk communications to overcome this divergence and promote effective responses in individuals and communities alike. By assessing the behavioural characteristics of those in low, moderate and high resilience groupings across the case studies (all flood risk areas) investigated, a number of guiding recommendations (some supported in research literature) for effective communications emerge. These are summarised as

1. Considerable information reservoirs, particularly web-based, containing vast quantities of relevant information for flood awareness and preparedness are in existence. The penetration levels of these (and other) resources however were shown in this study to be low. This did not appear to result from apathy in the project participants and in some instances, evidence was provided to suggest a willingness amongst people to engage in the flood management process. However, and perhaps for numerous reasons, this does not appear to be happening. Given that behavioural changes are more likely if they are self-motivated, rather than imposed, developing and raising awareness of current flood information sources such as websites, brochures and flood information campaigns offers potential for empowering individuals and communities to mitigate flood risk in an appropriate manner.

Various methods of promoting information sources emerged from the study and conduits which had particular traction amongst the public included dissemination through mass media sources (newspapers, radio, television) and circulation by post or through recognised access points (police stations, council offices, libraries). Dissemination of information sources through "lo-call" flood-help telephone lines was also considered useful but the financial implications of maintaining such a system make it less likely. Timing initiatives that raise awareness of useful flood information sources to coincide with periods when flooding features prominently in daily news or during anniversaries of previous floods was highlighted as being important for increasing the resonance of the message.

2. Results identify low levels of understanding amongst the public of the commonly used probabilistic terminologies used to describe risk uncertainty, even amongst those in high resilience groupings. Although literature suggests that the thought processes of the vast majority of individuals are binary (i.e. a flood will happen or won't happen) and that risk perception is based on a complex relationship that while including probabilistic estimates of flood risk, also includes situational, cognitive and affective factors of the individual, the need for easily understandable statements of risk remains. In some situations, conveying risk to at-risk communities can be improved by non-technical people tailoring risk information to produce clear, brief and focussed messages that suit local needs. Rather than using probabilistic terms to describe flood magnitudes, relating the consequences and impacts of different floods to similar events that occurred previously through audio and visual imagery, was also cited as being valuable.

3. The third and fourth recommendations in the communications framework are related. High levels of preparedness contribute to high levels of flood resilience. However, within the research sample, low self-assessed levels of preparedness were reported, even amongst those who were aware of the risk. Such results highlight an inclination amongst participants to delegate responsibility for flood mitigation to responsible authorities rather than take ownership of their own flood warning responses and self-protection measures. At no time in the course of this study was the mutual cooperation between relevant stakeholders (including 
the public) proposed as a means of advancing flood risk management. This was perhaps not surprising given that the roles and responsibilities of local and national flood risk authorities appeared to be not well understood by the public at large. The role of emergency services, particularly in flood incident management, was better understood. Therefore, for the creation of an effective flood risk management partnership between the relevant agencies and individuals/communities, these roles and responsibilities, and boundaries thereof must be publicised in flood communications. The use of social networking sites were suggested as a useful medium for this in that if used correctly, the public could assess the work of these authorities on an ongoing basis. Once roles and remits are clearly established in the consciousness of the general public, the responsibility of the public for self-protection can be differentiated from that of the flood risk management agencies. At this point, the further recommendation that flood preparedness information and the benefits of same be regularly provided, can be more successfully implemented. As with the case in (1) respondents cited well recognised access points (police stations, council offices, libraries) as suitable outlets for the provision of this information. In addition, dissemination through circulars from household insurers, where the financial benefits of taking preparatory actions could be outlined, was also considered to be a channel that could prove effective.

4. Communities in flood-risk areas are not homogenous and are comprised of individuals with varying social and demographic profiles. These differences are likely to be reflected in the many ways in which participants to the study preferred to receive flood related communications and warnings. A recommendation, therefore, is to utilise multiple channels of communication in disseminating flood warnings and general information pertaining to floods. Given short lead-times, this is especially important for flood warnings. With the rapidly developing world of communications, there is scope to utilise new communication methods in the social networking sphere. While these are likely to prove popular with younger members of society, results indicate that traditional communication methods are still required to cater to older residents in at-risk communities.

In the context of people-centred approaches to flood risk management, visible channels of communication between the responsible authorities involved in flood risk management and the public are required. These potentially provide flood risk managers with an invaluable stream of local flood knowledge that might not otherwise be captured. Such channels were not clearly evident within the case studies of this project and participants who had in the past attempted to engage with the authorities reported negative experiences. This undoubtedly contributed to the negative sentiment towards flood risk agencies that was epitomised in low levels of trust in these agencies (trust levels for emergency services were considerably higher). A key element in flood risk communications however is trust. Communication without trust and credibility is likely to have very little impact. Constructive interactions and dialogue between the relevant stakeholders in the flood risk management process will help foster trust. The benefits of flood risk agencies in contributing to the development of self-help groups in at-risk communities, communicating with existing local groups, utilising on-the-ground services, holding public events and setting up "lo-call" information lines were viewed as positive steps towards achieving this.

The key recommendations presented are useful for improving flood risk communications and their generic nature make them suitable for risk communications arising from other natural hazards. Furthermore, the results are not only applicable in the partner countries of the URFlood project but are considered to be easily transferrable elsewhere.

Acknowledgements. The URFlood project wishes to acknowledge the financial support made available by the Finnish Government, the Irish Office of Public Works, Istituto Superiore per la Protezione e la Ricerca Ambientale (ISPRA), the Scottish Government and the Environment Agency. Acknowledgments are also made to the 2nd ERA-Net CRUE Funding Initiative on "Flood resilient communities - managing the consequence of flooding".

Edited by: S. Mariani

Reviewed by: F. Grelot and two anonymous referees

\section{References}

Basher, R.: Global early warning systems for natural hazards: Systematic and people-centred, Philos. Trans. Roy. Soc. A, 364, 2167-2182, 2006.

Beck, U.: The risk society: Towards a new modernity, Sage, London, ISBN 0-8039-8346-8, 1992.

Brugnach, M., Dewulf, A., Pahl-Wostl, C., and Taillieu, T.: Toward a relational concept of uncertainty: About knowing too little, knowing too differently, and accepting not to know, Ecol. Soc., 13, 30, ISSN 1708-3087, available at: http://www.ecologyandsociety.org/vol13/iss2/art30/ last access: 30 June 2012, 2008.

Du Plessis, L. A.: A review of effective flood forecasting, warning and response system for application in South Africa, Anglais, 28, 9, ISSN 0378-4738, 129-138, 2002. 
EC: Directive 2007/60/EC of the European Parliament and the Council of the European Union of 23 October 2007 on the assessment and management of flood risks, published in the official journal of the European Union, L 288/27, November, 2007.

European Commission: Eurostat, http://epp.eurostat.ec.europa.eu/, 2011.

Faulkner, H., Parker, D., Green, C., and Beven, K.: Developing a translational discourse to communicate uncertainty in flood risk between science and the practitioner, AMBIO: A Journal of the Human Environment, 36, 692-704, 2007.

Frewer, L.: The public and effective risk communication, Toxicol. Lett., 149, 391-397, 2004.

Gheytanchi, A., Joseph, L., Gierlach, E., Kimpara, S., Housley, J., Franco, Z. E., and Beutler, L. E.: The dirty dozen: Twelve failures of the Hurricane Katrina response and how psychology can help, Am. Psychol., 62, 118-130, 2007.

Höppner, C., Buchecker, M., and Bründl, M.: Risk communication and natural hazards. Caphaz-net WP5 report, Swiss Federal Institute for Forest, Snow and Landscape Research (WSL) and WSL Institute for Snow and Avalanche Research SLF - Birmensdorf \& Davos, 2010

Horlick-Jones, T.: Citizen engagement processes as information systems: The role of knowledge and the concept of translation quality, Public Understanding of Science, 16, 259-278, 2007.

Horner, M. W. and Walsh, P. D.: Easter 1998 floods, Water Environ. J., 14, 415-418, 2000.

Irwin, A.: Citizen science: A study of people, expertise, and sustainable development, Routledge London and New York, 1995.

Kelley, K., Clark, B., Brown, V., and Sitzia, J.: Good practice in the conduct and reporting of survey research, Int. J. Quality Health Care, 15, 261-266, 2003.

Manyena, S. B.: The concept of resilience revisited, Disasters, 30, 434-450, 2006.

Marshall, N. and Marshall, P.: Conceptualizing and operationalizing social resilience within commercial fisheries in northern Australia, Ecol. Soc., 12, 2007.

Martens, T., Garrelts, H., Grunenberg, H., and Lange, H.: Taking the heterogeneity of citizens into account: flood risk communication in coastal cities - a case study of Bremen, Nat. Hazards Earth Syst. Sci., 9, 1931-1940, doi:10.5194/nhess-9-1931-2009, 2009.

Miceli, R., Sotgiu, I., and Settanni, M.: Disaster preparedness and perception of flood risk: A study in an alpine valley in Italy, J. Environ. Psychol., 28, 164-173, 2008.

Miles, B. and Morse, S.: The role of news media in natural disaster risk and recovery, Ecol. Econom., 63, 365-373, 2007.

Parker, D., Tapsell, S., and McCarthy, S.: Enhancing the human benefits of flood warnings, Nat. Hazards, 43, 397-414, 2007.

Pidgeon, N., Kasperson, R., and Slovic, P.: The social amplification of risk, Cambridge University Press, Cambridge, United Kingdom, 2003.

Pitt, M.: The Pitt review: Learning lessons from the 2007 floods. An independent review, Cabinet Office, London, 2007.

Raaijmakers, R., Krywkow, J. R., and van der Veen, A.: Flood risk perceptions and spatial multi-criteria analysis: An exploratory research for hazard mitigation, Nat.Hazards, 46, 307-322, 2008.

Renn, O. and Levine, D.: Trust and credibility in risk communication, in: Communicating risks to the public, edited by: Kasperson, R., and Stallen, P., Kluwer, Dordrecht, 175-218, 1991.
Roling, N. and Engel, P.: Information technology from a knowledge system perspective: Concepts and issues, Knowledge, Technology \& Policy, 1990.

Samuels, P., Gouldby, B., Klijn, F., Messner, F., van Os, A., Sayers, P., Schanze, J., and Udale-Clarke, H.: Language of risk. Project definitions, 2nd ed, 2005.

Schumm, S. A.: Erroneous perceptions of fluvial hazards, Geomorphology, 10, 129-138, 1994.

Sene, K.: Flood warning, forecasting and emergency response, Berlin, Springer Science and Business Media Deutschland, ISBN 978-3-540-77852-3, 2008.

Slovic, P.: The perception of risk, Earthscan Publications, London, ISBN 1-85383-527-7, 473 pp, 2000.

SPSS: PASW statistics 18.0, IBM, New York, http://www-01.ibm. com/software/analytics/spss/ last access: 30 June 2012, 2009.

Tapsell, S. M., Burton, R., Oakes, S., and Parker, D. J.: The social performance of flood warning communications technologies, Environment Agency, Technical Report W5C-016, ISBN: 184432 434 6, 2005.

Terpstra, T., Lindell, M. K., and Gutteling, J. M.: Does communicating (flood) risk affect (flood) risk perceptions? Results of a quasi-experimental study, Risk Anal., 29, 1141-1155, 2009.

Thrush, D., Burningham, K., and Fielding, J.: Flood warning for vulnerable groups: in: A review of the literature, edited by: Defra/Environment Agency, R \& D Technical Report W5C-018/1, ISBN 184432418 4, 2005.

Tinker, T. L. and Galloway, G. E.: How to communicate flood risks effectively, in: Journal of Business Continuity \& Emergency Planning, Henry Stewart Publications LLP, 193-200, 2009.

Tobin, G. and Montz, B.: Natural hazards: Explanation and integration, The Guilford Press, New York, 132-244, 1997.

Twigger-Ross, C., Fernández-Bilbao, A., Tapsell, S., Walker, G., and Watson, N.: Improving institutional and social responses to flooding - work package 1 final report. Environment Agency, 2009a.

Twigger-Ross, C., Fernández-Bilbao, A., Tapsell, S., Walker, G., and Watson, N.: Improving flood warnings: Final report, Environment Agency, Science Report: SC060019 - Work Package 1a, ISBN: 978-1-84911-058-7, 2009b.

United Nations: United Nations global survey of early warning systems: An assessment of capacities, gaps and opportunities toward building a comprehensive global early warning system for all natural hazards, http://www.unisdr.org/2006/ppew/info-resources/ ewc3/Global-Survey-of-Early-Warning-Systems.pdf, last access: date 30 June 2012, 2006.

UNISDR: United Nations international strategy for disaster risk reduction, 2005, 117-128, ISSN 2042-3195, doi:10.1002/atr.119.

Vahabi, M.: The impact of health communication on health-related decision making: A review of evidence, Health Education J., 107, 27-41, 2007.

Yamada, F., Kakimoto, R., Yamamoto, M., Fujimi, T., and Tanaka, N.: Implementation of community flood risk communication in Kumamoto, Japan, J. Adv. Transportation, 45, 117-128, 2011. 